This item was submitted to Loughborough's Research Repository by the author.

Items in Figshare are protected by copyright, with all rights reserved, unless otherwise indicated.

\title{
Soluble abrasives for waterjet machining
}

PLEASE CITE THE PUBLISHED VERSION

http://dx.doi.org/10.1080/10426914.2014.930949

\section{PUBLISHER}

(c) Taylor \& Francis

\section{VERSION}

AM (Accepted Manuscript)

\section{PUBLISHER STATEMENT}

This work is made available according to the conditions of the Creative Commons Attribution-NonCommercialNoDerivatives 4.0 International (CC BY-NC-ND 4.0) licence. Full details of this licence are available at: https://creativecommons.org/licenses/by-nc-nd/4.0/

\section{LICENCE}

CC BY-NC-ND 4.0

\section{REPOSITORY RECORD}

Boud, F., J.W. Murray, L.F. Loo, A.T. Clare, and Peter Kinnell. 2019. "Soluble Abrasives for Waterjet Machining". figshare. https://hdl.handle.net/2134/21436. 


\title{
Soluble Abrasives for Waterjet Machining ${ }^{1}$
}

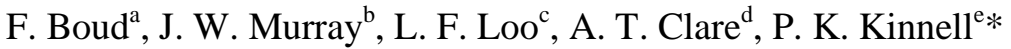 \\ Institute for Advanced Manufacturing, Faculty of Engineering, University of Nottingham, University Park, Nottingham, NG7 2RD, \\ UK

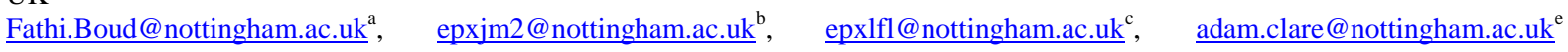 \\ Corresponding author: peter.kinnell@ @ottingham.ac.uk ${ }^{\mathrm{d}}$, Peterkinnell@ hotmail.com $^{\mathrm{d}},+44$ (0) 1158467680
}

Keywords: waterjet; soluble: abrasives; grit; embedment;

\begin{abstract}
The addition of hard abrasives to the jet in waterjet machining can improve machining rate, however, embedding of particles in machined surfaces is a limitation, which results in reduced fatigue life, and limits the application of well adhered subsequent coatings to the surface. In this study, softer soluble abrasives were investigated as a potential solution. Soluble abrasives yielded a higher material removal rate compared to plain waterjet, although were not as effective as traditional hard abrasives. Soluble abrasives reduced grit embedment on all four workpiece materials. A post-machining surface cleaning operation demonstrated that any remaining soluble abrasive could be removed.
\end{abstract}

\section{Introduction}

Abrasive waterjet (AWJ) is a useful technology for cutting a large range of materials across many industries, including ceramics, aerospace alloys and the mining industry [1-3]. The absence of a heataffected zone and relatively low cutting forces give the process advantages over other cutting technologies. The process involves impingement of a high pressure jet of water, usually with entrained abrasive particles, onto a workpiece. The action of multiple abrasive particle impacts combined with the high pressure waterjet gives rise to an erosion-based material removal process. Embedment of the abrasive particles in the workpiece is inevitable during processing. These particles are difficult to remove as they are often fully embedded in the workpiece material. Surfaces with embedded grit are known to exhibit poor fatigue behaviour compared with those without it due to the grit acting as a fatigue crack initiator [4]. In addition embedded grit may also generate serious problems for future manipulation and treatment of these surfaces, such as in welding or coating [5]. In some cases waterjet may be used for removal of unwanted surface layers that present possible surface integrity issues for components, for example in the case of Alpha case removal from superplastically formed titanium alloys [6]. In this case residual grit may also lead to a reduction in surface integrity so should be avoided. In macro-machining, secondary operations may be applied before usage of components which have been cut by waterjet, however waterjet is being increasingly used in micro- 
machining operations for intricate shapes and cuts, where final shapes and surface finishes are required [7], and therefore where surface finishing operations would not be appropriate. Thus, grit embedment due to AWJ is equivalent to surface contamination, and even minor grit contamination may not be acceptable for aero-engine and bio-implant applications. Reduction of grit embedment during machining has been the subject of prior research. For example it has been shown that waterjet milling at high traverse speed and at low impingement angles can reduce the percentage of machined area that is composed of embedded grit [8]. Despite this, no significant difference has been observed in terms of amount of grit embedment for different types of abrasive [9]. To fully eliminate the problem of grit embedment, plain waterjetting can be employed, although a much reduced material removal rate will result, which may therefore limit the commercial viability of the process [10].

To address this limitation, in this work two water-soluble abrasives have been investigated. In previous work water-soluble abrasives have been used to enhance cleaning [11], however they have not been investigated as a method of reducing grit contamination when using waterjet to remove materials from metal substrates. The potential benefit of soluble abrasives is that simple water based cleaning techniques with minimal environmental impact may potentially be employed to remove unwanted contamination. However, there is limited literature relating to the benefits in terms of material removal rate when soluble abrasives are used for metal cutting and milling. This study, therefore, aims to use the technique of water-soluble abrasive waterjetting as a solution to excessive grit embedment on workpieces during waterjetting and investigate the effect of this method on machinability. This work will provide information on the feasibility of such an adaptation of the standard abrasive waterjet process for the industrial setting, by investigating typical workpiece materials, as well as a range of machining parameters.

\section{Experimental Procedure}

Test coupons were cut from four different metals: Brass, Copper, Steel and Inconel. These were used so the effect of soluble abrasives could be established for both relatively hard and soft metals. The hardness and composition of each test material are shown in Table 1.

Table 1 Workpiece materials and properties

\begin{tabular}{|c|l|l|l|l|}
\hline & 63/37 Brass & Pure Copper & \multicolumn{1}{|c|}{ Inconel 718 } & 304 Stainless Steel \\
\hline Hardness (HV) & 113 & 93 & \multicolumn{1}{|c|}{290} & \multicolumn{1}{c|}{252} \\
\hline Composition & $\mathrm{Cu}-63.5$, & $\mathrm{Cu}-100$ & $\mathrm{Ni}-52.0, \mathrm{Fe}-18.9$, & $\mathrm{Fe}-71.0, \mathrm{Cr}-$ \\
$($ wt\%) & $\mathrm{Zn}-36.4$, & & $\mathrm{Cr}-18.9, \mathrm{Nb}-$ & $18.8, \mathrm{Ni}-7.76, \mathrm{Mn}$ \\
& $\mathrm{Fe}-0.08$ & & $\begin{array}{l}5.46, \mathrm{Mo}-3.27, \mathrm{Ti} \\
-0.97, \mathrm{Al}-0.54\end{array}$ & -1.85, \\
\hline
\end{tabular}

Using a waterjet machining centre, single lines of approximately one $\mathrm{mm}$ in width were milled in the test coupons. To ensure an effective comparison all the coupons were collocated on a single fixture 
and all milled at the same time. The system used a five-axis Water Jet System by Ormond with KMT Streamline SL-V 100D Plus waterjet intensifier, including a 100 Horsepower Pump capable of delivering water pressure of up to $414 \mathrm{MPa}$ with a Roctec 100 Nozzle. The nozzle diameter was 1 $\mathrm{mm}$, with nozzle length of $76 \mathrm{~mm}$ and orifice diameter of $0.3 \mathrm{~mm}$. The experiments were carried out using 4 different traverse speeds: 500, 1000, 2000 and $3000 \mathrm{~mm} / \mathrm{min}$ with a fixed standoff distance of $25 \mathrm{~mm}$ and a pressure of $275 \mathrm{MPa}$. The jet angle was set to be $90^{\circ}$ relative to the substrate surface.

Three abrasives were used in AWJ machining including garnet abrasive (GA) [12] and two types of soluble abrasives: MaxxStrip abrasive (MA) [13], and SoftStrip abrasive (SA) [14].

Table 2 Abrasive properties

\begin{tabular}{|c|l|l|l|}
\hline & \multicolumn{1}{|c|}{ MaxxStrip } & \multicolumn{1}{c|}{ Sofstrip } & \multicolumn{1}{c|}{ Garnet abrasive } \\
\hline Hardness (Mohs) & \multicolumn{1}{c|}{3.5} & \multicolumn{1}{c|}{2.8} & \multicolumn{1}{c|}{7.5} \\
\hline $\begin{array}{c}\text { Composition } \\
\text { (wt\%) }\end{array}$ & $\mathrm{MgSO}_{4}-55 \%$ & $\mathrm{NaHCO}_{3}-99.9 \%$ & $\mathrm{SiO}_{2}-38 \%$ \\
& $\mathrm{MgO}-18.4 \%$ & $\mathrm{Na}_{2} \mathrm{CO}_{3}-0.01 \%$ & $\mathrm{Al}_{2} \mathrm{O}_{3}-22 \%$ \\
& $\mathrm{~S}-15.35 \%$ & $\mathrm{As}^{-}$trace & $\mathrm{Fe}_{2} \mathrm{O}_{3}-30 \%$ \\
& $\mathrm{H}_{2} 0-8.4 \%$ & $\mathrm{SO}_{4}-$ trace & $\mathrm{TiO}_{2}-1 \%$ \\
& $\mathrm{CaSO}_{4}-2.8 \%$ & $\mathrm{Cl}-$ trace & $\mathrm{MnO}-1 \%$ \\
& & & $\mathrm{CaO}-1 \%$ \\
& & & $\mathrm{MgO}-7 \%$ \\
\hline
\end{tabular}

MaxxStrip is the mineral Kieserite, and contains $55 \% \mathrm{MgSO}_{4}, 18.4 \% \mathrm{MgO}, 15.35 \% \mathrm{~S}, 8.4 \% \mathrm{H}_{2} \mathrm{O}$, and $2.8 \% \mathrm{CaSO}_{4}$. SofStrip contains $99.9 \%$ sodium bicarbonate, and $0.01 \%$ sodium carbonate, along with a trace of chloride, sulphate and arsenic. The soluble abrasives were selected to fulfil a range of hardnesses quoted here on the Mohs hardness scale, the Maxxstrip having 3.5, and the SoftStrip with 2.8, while the hardness of the non-soluble garnet abrasive was 7.5-8. Figure 1 shows the shapes and sizes of the three types of abrasives. GA and SA are of similar size, whilst the size of MA particles can be observed as much larger. All abrasives exhibited sub-angular shapes. 


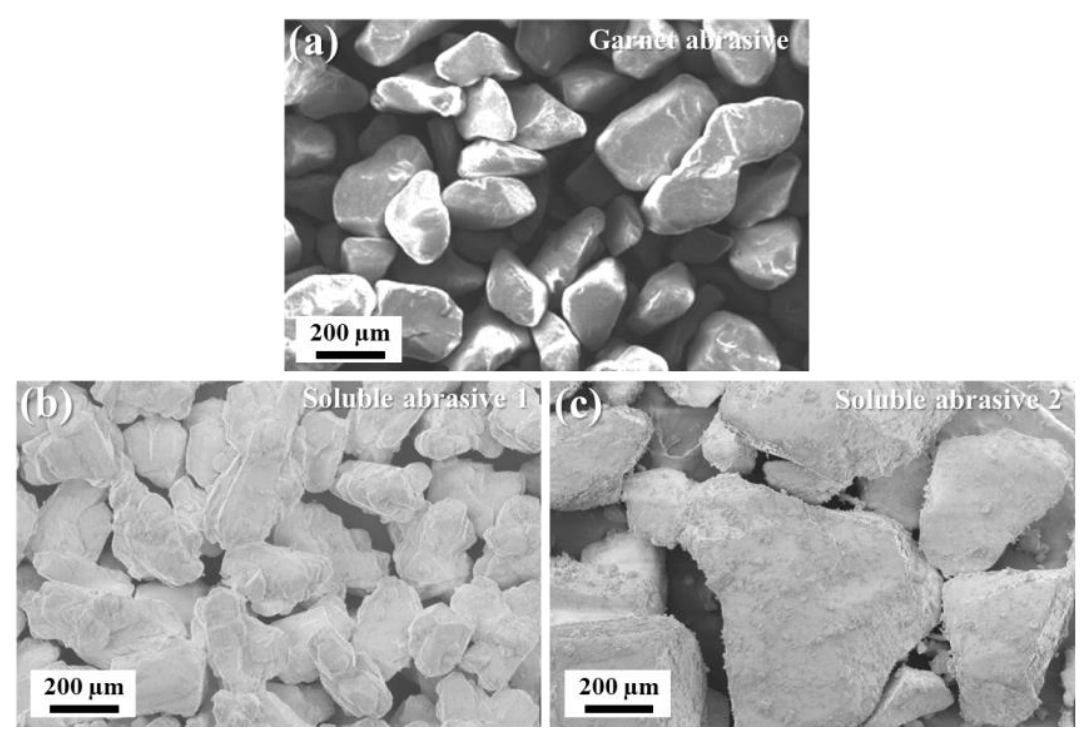

Figure 1 (a) GMA garnet abrasive (mesh size 80) (b) Soluble abrasive 1 - Softstrip (mesh size 60) (c) Soluble abrasive 2 - Maxxstrip (mesh size 20-40).

Microscopy was performed using a Philips XL 30 SEM, using both secondary electron (SE) and backscattered electron (BSE) imaging. Profilometry was performed with a Talysurf CLI1000 profilometer with a laser displacement sensor, lateral resolution $1 \mu \mathrm{m}$.

\section{Material removal rate and surface roughness}

Results for material removal rate and surface roughness can be seen for all samples in Figure 2. For all four workpiece materials, the standard garnet abrasive performed better in terms of MRR under all traverse speeds as expected. The highest MRR of $2002 \mathrm{~mm} 3 / \mathrm{min}$ was achieved using a copper workpiece and lowest traverse speed of $500 \mathrm{~mm} / \mathrm{min}$, although this was reduced to 990 with the higher traverse speed of $3000 \mathrm{~mm} / \mathrm{min}$. Out of the soluble abrasives, the harder Maxxstrip abrasive (SA2) performed better in terms of MRR than PWJ and the softer SA1 abrasive for all workpiece materials. For the harder materials of Inconel and Steel, both PWJ and the SA1 abrasive produced a negligible depth of cut for all traverse speeds and therefore the MRR was too low to be measured. 


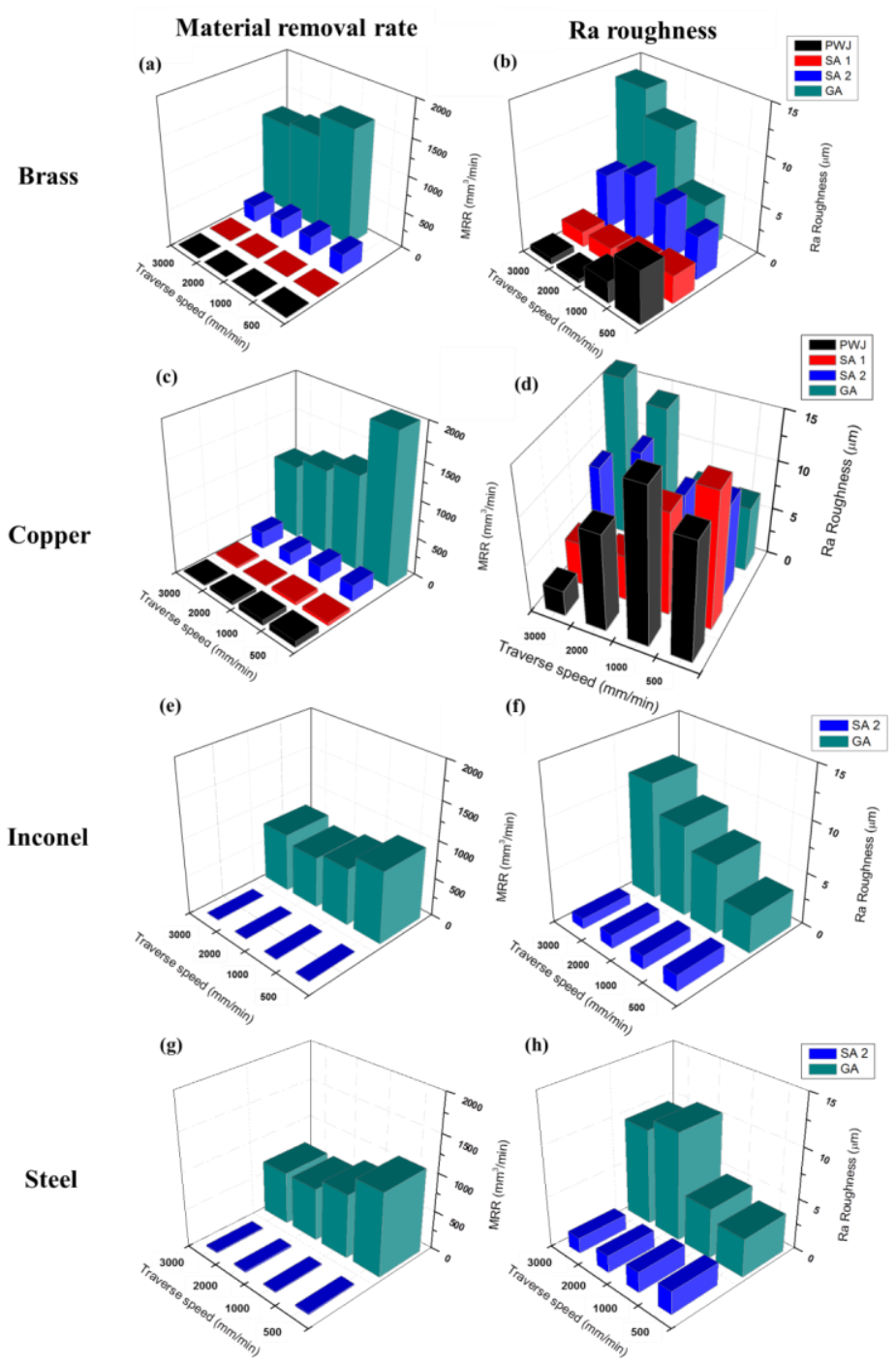

Figure 2 The MRR and Ra roughness resulting from variation in traverse speed for all workpiece materials and all abrasive types.

Despite the superior machining rates under all setups for the standard insoluble garnet abrasive, MRR was significantly higher in all situations for the harder SA2 abrasive compared with both PWJ and the SA1 abrasive. Under machining of the softer workpieces of brass and copper, the MRR when using the SA2 soluble abrasive was much closer to the MRR achieved using standard garnet. For example when machining brass, MRR using garnet abrasive was between 16\% - 20\% higher than SA2 soluble abrasive, and was between $11 \%$ - 23\% higher when machining copper, dependent upon traverse speed. In terms of MRR, the garnet abrasive performed better compared to the SA2 soluble abrasive by a factor between 39 and 59 when compared to cutting steel, traverse speed dependent; and the cutting of Inconel where the factor was even higher, between 66 and 98 times that of the soluble abrasive. In almost all cases the MRR when using the soluble abrasives relative to when using the garnet abrasive increased when using higher traverse speed, with exception when the garnet abrasive benefitted from cutting Inconel and Steel at the highest traverse speed. 
Ra roughness of the machined workpiece using standard garnet abrasive, under all setups, increased with increasing traverse speed, with the exception of cutting steel where cutting at $3000 \mathrm{~mm} / \mathrm{min}$ produced a slightly lower roughness than at $2000 \mathrm{~mm} / \mathrm{min}$. This trend with traverse speed however was not followed by the soluble abrasive machining nor with plain waterjet suggesting that soluble abrasive waterjet machining would be a useful method for surface finishing. The copper workpiece produced the roughest surfaces for all abrasives, the highest value being $16.2 \mu \mathrm{m}$ Ra for PWJ at 1000 $\mathrm{mm} / \mathrm{min}$ traverse speed. Garnet abrasive under highest traverse speed produced a similar level of roughness of $16.1 \mu \mathrm{m} \mathrm{Ra}$, despite a much lower value of $6.85 \mu \mathrm{m}$ at lowest speed. Under machining with soluble abrasive 2 , the highest roughness was $12.4 \mu \mathrm{m}$ with a lowest value of $9.53 \mu \mathrm{m}$. For the brass workpiece, roughness values were consistently lower, with soluble abrasive 2 producing 7.17 $\mu \mathrm{m}$ as the highest roughness and $4.47 \mu \mathrm{m}$ as the lowest. Soluble abrasive 1 produced again lower roughness values between 1.62 and $2.85 \mu \mathrm{m}$, despite the MRR with this setup being much lower. For cutting both Inconel and Steel, the SA2 produced a consistently lower roughness than when cutting with garnet abrasive, for example a value of $1.03 \mu \mathrm{m}$ was yielded under highest traverse speed compared to $11.3 \mu \mathrm{m}$ from the garnet abrasive. This may be related with the abrasive characteristics, where the hardest abrasive (garnet) produced the rougher surfaces, where it has been observed that the harder the particle the higher the SR [15].

\section{Grit embedment}

Grit embedment is widely acknowledged as a problem in the AWJ process, different technologies have been developed with the aim to reduce this phenomenon, among them the recent technique introduced by Huang: hybrid waterjet cleaning (HWJC), that uses abrasive waterjet machining followed by plain waterjet machining to reduce the effect of the grit embedment in the target materials. This technique has proved to be effective in improving the surface integrity of the materials machined by waterjet, however it has not yet been shown possible to remove completely the abrasive particles embedded in the workpiece [16]. Back-scattered electron (BSE) imaging was exploited to show the overall change in grit presence on the surfaces over an area of approximately $1 \mathrm{~mm}^{2}$. BSE imaging can show clearly the distribution of particles containing elements of lower or higher atomic numbers, so although quantification was not possible, trends can be clearly shown. As can be seen in the array of BSE images shown in Figure 3, at the medium traverse speed of $1000 \mathrm{~mm} / \mathrm{min}$, both soluble abrasives resulted in reduced grit embedment for all four workpiece materials, compared to the standard garnet abrasive. Across all materials, copper exhibited the most extensive grit embedded surfaces under machining with soluble abrasives. Abrasive particles on copper were typically embedded in craters and cavities, which are locations where they were partially concealed by surrounding workpiece material, this may be similar to flash concealment in cold spray. It is not clear whether these surface depressions were created directly by the impact of abrasive particles, or simply 
by the force of hydraulic penetration, thereby creating regions from which it is difficult for abrasive particles to escape after embedding. If the latter is the case, the mechanism of grit contamination on copper would appear to be distinct from the other materials in this study, whereby simple trapping of the particles in the rough surface is responsible for such grit contamination.

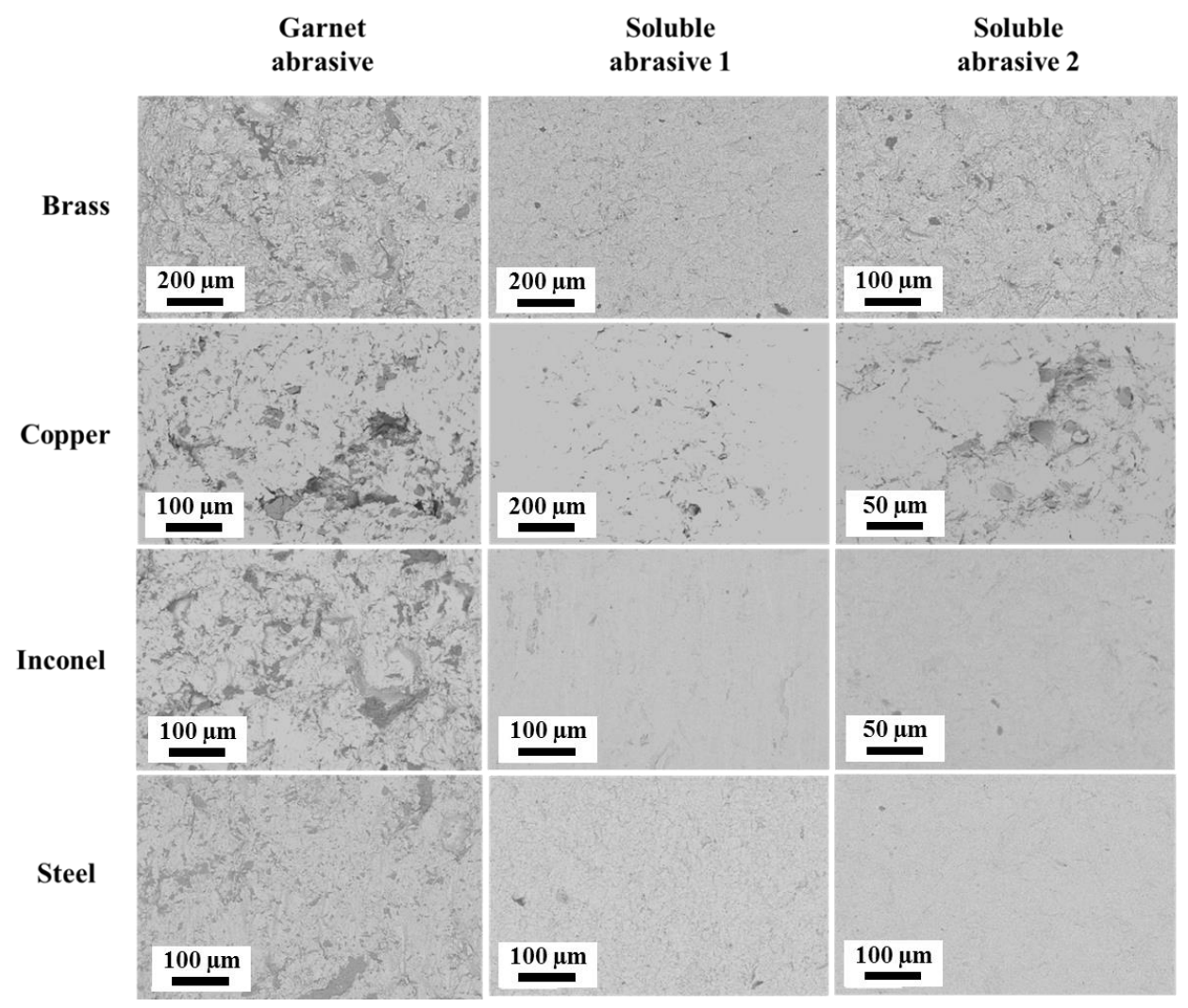

Figure 3 BSE images showing grit embedment at traverse speeds of $1000 \mathrm{~mm} / \mathrm{min}$

For the other three workpiece materials, the brass machined surface contained less grit contamination than the copper, for both soluble abrasives. The SA1 abrasive resulted in a relatively clean surface with only few embedded particles. The harder SA2 abrasive produced a more contaminated surface on brass, although this was still less extensive than on the copper workpiece. For both steel and Inconel, almost entirely grit free surfaces were produced. For the SA1 abrasive, this could be explained by the negligible depth of cut and MRR, thereby leaving no craters or crevices aiding grit embedment. For the SA2 abrasive, where the cut profiles were clearly seen with a machined surface, only very few embedded particles were observed. This difference between the behaviour of the SA2 on the materials of brass and copper and materials of steel and Inconel, is explained by the much lower hardness of brass and copper, and therefore the ductile fracture and plastic deformation taking place on these surfaces resulted in crevices suitable for grit embedment. This relationship with hardness would also be explained by the worse grit contamination taking place on the softest workpiece of copper.

\section{Grit removal}


While the erosion rates of soluble abrasives are significantly lower than conventional abrasives they are more easily removed from the workpiece post machining. Since the soluble abrasives used in this study are soluble in water, in order to investigate the removability of the embedded soluble particles, AWJ-eroded surfaces on copper (for which grit embedment for all types of abrasives was more prominent) were selected for a secondary cleaning operation. After either immersion in water for different durations or ultrasonic cleaning, subsequent SEM observation of the extent of grit embedment was performed. Cleaning operations were carried out using the procedure shown in Table 3. After each step of the cleaning operation, the cleaned surfaces were investigated using SEM. For the water immersion test, the samples were placed in a container with 10 litres of water. The water was changed frequently to ensure that the saturated solubility of the soluble abrasives in water was not reached. In the ultrasonic cleaning process, the cleaning solvent was plain water.

Table 3 Procedure for soluble abrasive cleaning process

\begin{tabular}{|c|c|c|c|}
\hline Step & Operation & Duration & Notes \\
\hline Step 1 & Immersion in water & 8 hours & Change water every 2 hours \\
\hline Step 2 & Immersion in water & 24 hours & Change water every 6 hours \\
\hline Step 3 & Ultrasonic cleaning & 10 minutes & \\
\hline
\end{tabular}

Figure 4 shows the changes of grit contamination over three regions on AWJ-resulted copper surfaces using SA. Three different regions were compared due to the difficulty in locating the exact region previously analysed, given the changing level of contamination on the surface. However, the regions selected after each cleaning operation for observation were representative of the features of grit contamination over the entire surface. It was found that after 8 hours of immersing into water, the area of grit contamination was reduced, but particles diameters of approximately $50 \mu \mathrm{m}$ were still observed. After 32 hours of immersion in water, the area of the surface covered in contamination was further reduced; and the larger SA1 particles were rarely observed on the surface. It is thought that a water circulation system may also encourage more effective dissolution by continuously supplying fresh water to the surfaces and maintaining a low saturation of abrasives in the water. The ultrasonic cleaning however resulted in a highly clean surface with only rare particles remaining. In this case, the SA particles were removed even from deep grooves and cavities; the most common locations of grit embedment. The dark coloured lines still present in the BSE image are due to the rough topography and deep grooves on the surface. Based on this study, a secondary cleaning operation is proposed as feasible for the final elimination of grit from the surface, if a pure surface is sought for high value parts. This is despite initial grit embedment being shown by this study to significantly reduce for the majority of workpiece materials and parameters from the use of soluble abrasives alone. 


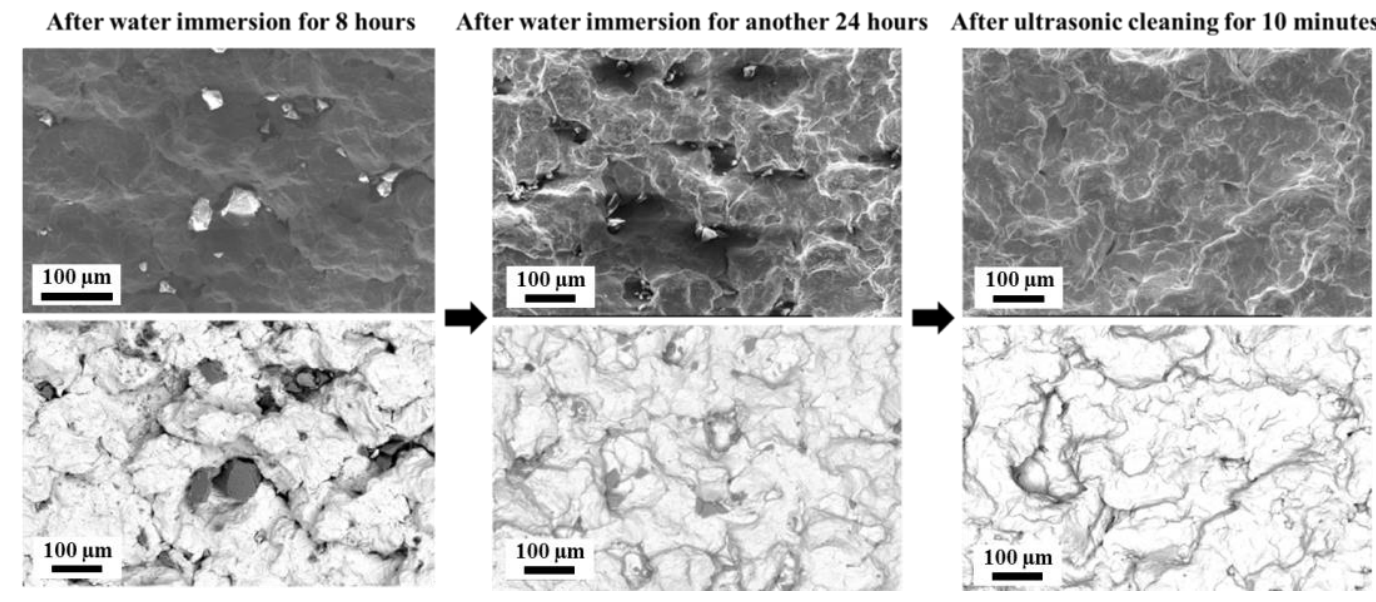

Figure 4 Change of grit contamination over three different regions on the AWJ treated copper surface using Soluble Abrasive 1 at traverse speed $1000 \mathrm{~mm} / \mathrm{min}$. Both SE and BSE images are shown.

\section{Conclusions}

This study has shown that within the experimental conditions, soluble abrasives are unlikely to result in grit contamination on the treated surfaces of relatively hard and less ductile materials - Inconel and steel. However, the soluble abrasives still resulted in notable grit contamination on the more ductile materials - copper, aluminium and brass, despite a much smaller proportion of contaminating area being observed in comparison to the GA. In addition, the morphology of surfaces on all materials treated by soluble abrasives indicates similar damage mechanisms taking place compared with that treated by PWJ. The behaviour of grit embedment seems to be affected by the morphology of AWJresulting surfaces. Particles were found more likely to be trapped in surface depressions, such as cavities and crevices.

Water cleaning and ultrasonic cleaning operations were carried out to investigate the feasibility of post-machining cleaning of the embedded soluble abrasives. The results revealed that Maxxstrip abrasive particles were hardly dissolved even for immersion up to 32 hours, and while Softstrip Abrasive particles can be slowly dissolved, however, there is still a significant amount of grit remaining on the surface. Compared to water immersion, ultrasonic cleaning is shown to be a more effective method to remove embedded soluble abrasives. Particularly, on the copper surface contaminated by SA particles, ultrasonic cleaning can almost completely remove the contaminating Softstrip abrasive grit within 10 minutes.

The soluble abrasive Maxxstrip abrasive (SA2) achieves greatly enhanced material removal rate compared to plain water, especially when machining Brass and Copper; for Brass the rate is approximately 20 times better and for Copper approximately 5 times better. The benefits of using soluble abrasives to enhance machining processes has been demonstrated, however further work is still required to optimise the use of soluble abrasives. In light of the low dissolution rate of the two 
soluble abrasives in water as well as the difficulties to apply large ultrasonic cleaning facilities for manufacturing use, future work will be required to investigate the selection of a suitable solvent in which the MA and SA particles can be dissolved quickly.

\section{References}

1. Momber, A.W. and R. Kovacevic, An energy balance of high-speed abrasive water jet erosion. Proceedings of the Institution of Mechanical Engineers, Part J: Journal of Engineering Tribology, 1999. 213(6): p. 463-472.

2. Karakurt, I., G. Aydin, and K. Aydiner, An experimental study on the depth of cut of granite in abrasive waterjet cutting. Materials and Manufacturing Processes, 2012. 27(5): p. 538-544.

3. Ay, M., U. Çaydaş, and A. Hasçalik, Effect of traverse speed on abrasive waterjet machining of age hardened inconel 718 nickel-based superalloy. Materials and Manufacturing Processes, 2010. 25(10): p. 1160-1165.

4. Singh, J. and S.C. Jain, Mechanical Issues in Laser and Abrasive Water-Jet Cutting. JomJournal of the Minerals Metals \& Materials Society, 1995. 47(1): p. 28-30.

5. Chen, F.L., et al., Minimising particle contamination at abrasive waterjet machined surfaces by a nozzle oscillation technique. International Journal of Machine Tools and Manufacture, 2002. 42(13): p. 1385-1390.

6. Chillman, A., et al., High pressure waterjets - An innovative means of alpha case removal for superplastically formed titanium alloys. 2010. p. 103-111.

7. Liu, H.T., Waterjet technology for machining fine features pertaining to micromachining. Journal of Manufacturing Processes, 2010. 12(1): p. 8-18.

8. Fowler, G., P.H. Shipway, and I.R. Pashby, A technical note on grit embedment following abrasive water-jet milling of a titanium alloy. Journal of Materials Processing Technology, 2005. 159(3): p. 356-368.

9. Boud, F., et al., Abrasive waterjet cutting of a titanium alloy: The influence of abrasive morphology and mechanical properties on workpiece grit embedment and cut quality. Journal of Materials Processing Technology, 2010. 210(15): p. 2197-2205.

10. Kong, M.C., D. Axinte, and W. Voice, Aspects of material removal mechanism in plain waterjet milling on gamma titanium aluminide. Journal of Materials Processing Technology, 2010. 210(3): p. 573-584.

11. Kulekci, M.K., Processes and apparatus developments in industrial waterjet applications. International Journal of Machine Tools and Manufacture, 2002. 42(12): p. 1297-1306.

12. Garnet Abrasive. 12/05/14]; Available from: http://www.universalminerals.com/WE_CMS/documents/pdfs/sharpjet_technicaldata.p df.

13. MaxxStrip Abrasive. 18/12/13]; Available from: http://www.universalminerals.com/WE CMS/documents/pdf2/MaxxStrip\%20data.pdf.

14. SofStrip Abrasive. 18/12/13]; Available from: http://www.universalminerals.com/WE CMS/documents/pdf2/SofStrip\%20Data\%20Sh eet.pdf.

15. Fowler, G., I.R. Pashby, and P.H. Shipway, The effect of particle hardness and shape when abrasive water jet milling titanium alloy Ti6Al4V. Wear, 2009. 266(7-8): p. 613-620.

16. Huang, L., P. Kinnell, and P.H. Shipway, Parametric Effects on Grit Embedment and Surface Morphology in an Innovative Hybrid Waterjet Cleaning Process for Alpha Case Removal from Titanium Alloys. Procedia CIRP, 2013. 6(0): p. 594-599. 